view of conservation. We do have preservation statutes, such as the national and provincial parks statutes, and the ecological reserves legislation, but a charter of rights in nature seems far off. After all, we've only just achieved a charter of rights for persons.

One may ask whether it is important to aspire for laws that go beyond "wise-use" conservation. One may also ask what this examination of conservation ethics has to do with the underlying theme of this conference, which is to seek understanding as to how the management of forestry and wildlife can be better integrated. If by "integration" we mean only that policies and practices should be designed to avoid unnecessary harm to one natural resource by the exploitation of another, the importance of such "integration" is beyond question. But "integration" of resource management portfolios potentially means much more.

It is clearly a precondition of "wise-use" conservation, for, without such integration, the trade-offs cannot be made that are necessary if the mix of resource uses is to achieve optimum benefits for society. However, integration by itself provides no measure for these trade-offs. The principles of "wiseuse" conservation do, but their utilitarian emphasis invariably reduces wildlife to second place in competition with trees. Some Solomon's scale is needed if intrinsic values in wildlife are ever to overbalance the economic values of the forest. Nor is much comfort to be gained from the efforts of evaluation economists to find shadow prices for lost hunting opportunities to be weighed against the hard currency of timber sales.
If our society does value wildlife and their habitat for their own sake, and wishes to impose on governments and developers a mandate to preserve these values notwithstanding the higher economic values that harvesting the forests can provide, the only alternative to the exercise of raw political power is the enactment of charter-like laws that establish principles of preservation and strategies for achieving them. These laws may be seen as the embodiment of society's fundamental choices about its natural environment. I have spoken as if only wildlife were at stake. The forest lands are imperiled too, as industrialization and acid rain take their toll. Society must make its choices about the natural environment, for without clear choices in the laws governing natural resources, no degree of integration in management practices can arrest the deterioration in life support systems so clearly documented in the World Conservation Strategy (IUCN, 1980).

\section{References}

IUCN (International Union for the Conservation of Nature and Natural Resources). 1980. World Conservation Strategy. Gland, Switzerland. Portfolio and maps.

Dale, J.H. 1968. Pollution, Property and Prices. Univ. Toronto Press, Toronto, Ont. $111 \mathrm{p}$

Roundthwaite, I. 1982. The national parks: An endangered species Sask. Law Rev 46: 43

Rueggeberg, H. and A.R. Thompson. 1984. Conservation in the north: A legislative analysis. Westwater Res. Centre, Univ. British Columbia, Vancouver, BC. 50 p.

Thorne, G. 1983. Standing in the judicial review process. WCELRF Newsletter 8(2): 5 .

\title{
The Problems of Integrating Forestry and Wildlife Management: The Foresters' Viewpoint
}

\author{
by
}

M.R. Innes 1

\begin{abstract}
The long-established professions of biology and forestry harbour conscientious and intelligent practitioners. Communication between the two professions has traditionally been poor but is slowly improving. For integrated resource management to be successful, an acceptable planning framework must be established; there must be clearly enunciated and agreed-to objectives; cooperation between biologist and forester will be mandatory; and abnormally heavy commitment of time will be necessary. The cost of implementation will be a stumbling block.
\end{abstract}

Key words: Forestry, multiple use, integration, wildlife management.
'Manager of Forestry. Abitibi-Price Inc., Toronto-Dominion Centre, Toronto, Ontario M5K 1 B3

\section{Introduction}

The main problem with integration is that there isn't any. It just hasn't been happening. There are, however, examples of cooperative projects between forestry and wildlife jurisdictions and a brief examination of one of these with which I am familiar will help to uncover some of our traditional integration problems.

This cooperative project was that of modifying harvest patterns to assist moose management in northeastern Ontario. The government biologists approached Abitibi-Price with a carefully thought-out plan for modified cutting in Bragg Township. They explained that the local moose population was declining; that Bragg Township was an area of known moose concentration; that modified harvesting would provide winter cover, browse, and travel corridors; that a follow-up study would be done; and so on. All in all, it was a masterful job and a slick presentation. But beyond some comforting words in the forest management plan, moose management wasn't one of the company's objectives and the proposal was consequently politely declined on the basis that it would cost too much. The discouraged biologists returned to their maps, drastically 
reduced their plan, and doggedly presented it again. This time after some negotiating, a modified version was accepted by both parties. The work was carried out as planned and what came to be known by our foresters as "moose motels" were left in the cut. But the pattern was such that it was uneconomical for the company to return for the leave blocks and these were consequently bypassed.

The net result was partially happy biologists, unhappy foresters, and presumably happy moose. I say presumably happy since the follow-up studies have not been completed due to a lack of funds.

This project was labelled as a success, and it was in terms of cooperation; yet it highlights a number of areas that require attention before we speak of integration. The next few paragraphs explore some of these problem areas to see whether a potential solution does exist.

\section{Requirements for Integration \\ Commitment}

First there has to be mutual commitment to manage for wildlife. On the part of the foresters, it isn't good enough to offer lip service if anything meaningful is to be accomplished; e.g. polite words about wildlife management in forest management plans. On the part of the biologists, a failure to become knowledgeable about on-the-ground harvesting operations doesn't better their understanding of ways to manipulate the forest cover; e.g. indiscriminate marking of reserves on harvesting approvals without first conducting on-site inspections. In my perception, about $80 \%$ of the mutual commitment problem lies in the two fields of communications and policy.

\section{Communication}

There is definitely a communications gap between the two professions. Although it can't be blamed solely on numbers, in work places where foresters congregate, they out-number biologists. No doubt the converse is also true. And perhaps this gap is maintained to at least some extent at the field level by the necessity for wild life biologists to spend less time in the field than they would like due to a lack of funding for on-theground management projects. To be blunt about it, foresters often perceive them to be research (if not desk) oriented.

So foresters and biologists don't rub shoulders in the bush as often as they should. Add to the confusion the fact that few - if any - foresters read the professional journals in which biologists publish their articles. At best there may be several wildlife articles per year in the forestry journals. Lack of understanding usually breeds mistrust and I can't help but wonder whether this hasn't occurred here on both sides.

\section{Policy Formulation and Acceptance}

As a practicing forester, before including wildlife management as one of my objectives, I have to know and accept that there is an approved policy objective to manage for a certain species or groups of species. Furthermore, the objective, even if clearly enunciated and obviously approved, must be accepted by may superiors. It sounds obvious doesn't it? But look at what has happened in the Crown management units in Ontario. The forest management planning process has been in existence for many decades. There is a long-standing policy of moose management. Somehow the two have not become integrated at the field level. Why? There are two major reasons. Firstly, The policy of moose management has not been accepted as a priority by the senior forestry hierarchy in government. Secondly, the policy has not been translated into a set of objectives and consequently funding has not made available for the biologist to implement the policy. Whether we like it or not, we live in an industrial society, which so far has evaluated choices on the basis of economic criteria. I suggest to you that policies without funding are like cars without wheels - they may appear attractive but they don't go anywhere. If lack of commitment to policy has been a major impediment to implementing wildlife management at a governmental level in Ontario, consider the chances of success at an industrial level, such as the forest management agreements.

\section{Planning}

The entire field of planning currently presents problems to integration. Inventories which, within known limits of accuracy, define that location, extent, and nature of the resource, are a pre-requisite to management. Foresters predicate their planning upon these inventories and their periodic update Wildlife managers face a much more difficult task. Most the forested areas of Canada which have an economic potential have been inventoried. Such is not the case for wildlife. Foresters have traditionally written their management plans in isolation from the biologists. This is not to say that biologists don't have plans, for they do. So what results is a set of management units - one for forestry and one for wildlife each with different boundaries. Each side has very good reason (e.g., data base management) for wanting those boundaries to remain intact. Whose management plan becomes the vehicle for implementation? In some people's eyes, the question is instantly rephrased to "who becomes subservient?' The entire planning framework is a difficult issue, which must be resolved at a local level on a professional plane, before any progress will be made.

Permit me to turn for a moment to the topic of professionalism. Each of our professions must be described as founded in part on art and in part on science. There is consequently no single solution to a given problem. Let me remind you that it is a commonly observed phenomenon that when you place five foresters in a room and tell them to solve a problem, you get six answers. Seriously though, the variety of possible solutions still provides difficulty in reaching a definitive, agreed upon answer by foresters for a forestry problem. There is absolutely no doubt that this difficulty will be intensified when dealing with two professions rather than the one. Couple to this the fact that there are but few local examples in eastern Canada of demonstrated results of successful integrated management. The bottom line will have to be a high degree of mutual professional respect and trust if each side is to accept what the other says in good faith.

\section{Solving Strategy Conflicts}

How do we solve the conflict of operational strategies when these arise? Nobody likes to compromise. In the example I quoted previously, the moose biologist had put together the most attractive package for moose that he was able to devise His obvious priorities were to assist the moose. Our foresters had their priorities of harvesting the area as cheaply as possible, removing all merchantable wood, and doing this so that the site could be effectively regenerated. Obviously moose weren't a part of their operational strategy. Subsequently discussions revealed the lack of knowledge of both parties of the parameters used by the other in formulating their particular strategy. Close cooperation is required to both understand and agree upon the details of the reasons for conflict, to identify the trade-off options and to assign values to them. Until this is done, a mutually agreed-to strategy, which will be known to each side as a compromise, will be impossible.

I now want to turn to the question of what I, as a forester, require from my professional colleague in terms of assistance. Let's assume that I and our respective employers have agreed that it is important to include wildlife management as one of the objectives in a resource management plan.

Before we can even begin, there has to be a planning 
process that permits integration. If the forest estate is in private ownership and the owner employs both foresters and biologists, we shouldn't have a problem. But, to describe the other extreme, consider the case in which the Crown owns the land, the Crown has dedicated it to a company under a forest management agreement, management planning is the responsibility of the company and plan approval rests with senior government foresters. Here we obviously do have a problem with an integrated planning process. In Ontario where where the last mentioned example is a real life situation, the government has proposed the following solution. The traditional forest management plan will provide the planning framework. A special category of land, on which the forest cover will be handled in a manner potentially different from normal circumstances has been established. This is called a modified management area (MMA). At an early stage in the planning process the appropriate area of expertise will have an opportunity to identify MMAs necessary to the support of their particular programs. For example, a "no cut" fringe of timber along a cold water fishery stream or an area to be modified cut for moose management would be identified as MMAs. The appropriate management prescriptions are drawn up by the biologist and discussed with both government and company foresters before being finalized. They are then to be included in the forest operating plan, implemented by the company in the field, and assessed by the government. This process is a new one and it remains to be seen how well it will work at a field level, if it works at all.

Another prerequisite is that of commitment. At the risk of overstressing a point, I shall repeat that all of the parties involved must recognize and accept the wildlife management objectives. I mention it again because there is no shadow of doubt in my mind that industry will not willingly participate in wildlife management if it entails increased costs of operation. This fact means to me that foresters and biologists will each have to become more cognizant of the others' profession and that each, when committed to integrated management, must be prepared to spend considerable time in searching for nocost or least-cost alternatives to meet the integrated resource management goals.

This will to work together translates directly into time. The preparation of a 20-year forest management plan and a 5year operating plan usually takes a forester a full year. I would expect that my biologist colleague would have to be prepared to devote about a third to half of a year to our integrated resource management plan.

\section{What Must the Biologist Contribute}

How would the biologist contribute? First by being intimately familiar with the management area. This implies a residency of at least three years in the area. It also implies that he or she knows the forest, the wildlife populations, and their preferred habitats. But also, the biologist must be familiar with the normal type of road building, harvesting and forest renewal practices in the area. In other words, a lot of time will have to have been spent in the bush. Theoretical knowledge by itself is not adequate.

I need to know which species are important. I also need to know why. And I am sure that most foresters would appreciate being lent pertinent articles about the management techniques for these species. To the biologists: don't be afraid to offer. To the foresters: don't be shy about asking. It might be appropriate to begin by concentrating on one or two species given that we have history of integrated management.

Once the biologist has told me what is important for wildlife, I would like to know what I must avoid (if anything). Does he have a wish list of restrictions affecting my harvesting, silviculture or access operations? If the answer is "yes", then l'd like to know immediately because serious discussion will be required. At the same time, a description and explanation of the wildlife inventory, habitat requirements, and food requirements would be of use to me as I prepare the first draft of my silvicultural prescriptions.

\section{Joint Plan Preparation}

True integration dictates that the management plan be jointly written by the biologist and the forester. This is particularly appropriate in the key areas of access, harvesting and forest renewal. This should be a process of the biologist and forester having sufficient knowledge of each other's concerns that the first draft stage of the plan will recognize the major trade-offs that might have to occur. It is important that these trade-offs be identified "up front" and that furthermore, they be quantified if at all possible in dollar values. As I mentioned earlier, one of the causes of failure of integration is the lack of funding for it and the extra cost associated with it. In these days of financial restraint, I can't see funding increasing dramatically; so that leaves us with the only remaining alternative of attempting to reduce the cost of implementation.

Reducing the cost means that we both must be innovative in seeking solutions to new problems. But before either of us can do that, we must each fully understand the entire problem. This means breaking everything down to the smallest components possible and dealing from first principles. Although compromises on both sides will no doubt have to be made, I am optimistic that solid progress is possible in this area. I should point out that innovation usually carries a risk. Specifically, habitat manipulation has long-term effects, which are often difficult to predict. Perhaps this is a field in which computerized simulation can be of benefit in forecasting changes on wildlife populations.

\section{Assessment}

Nothing succeeds like success, as the old saying goes. Therefore it is going to be necessary to prove to ourselves, to our superiors, and to the public that integrated resource management can work. To do this we must formulate assessment and feedback procedures. To do this we must formulate assessment and feedback procedures. A part of integrated resource management must be the process of establishing a reference point, defining the results achieved, and modifying our procedures in the light of experience. I would expect my biologist colleague to design and implement these for his areas of concern. Again the delicate question of cost is raised. My answer this time is that it is a cost of doing business and the wildlife program had best be prepared to fund data collection to prove that they can get results.

Most habitat management will occur during the harvesting and will be done by the ordinary bushworker. It would be appropriate, helpful and encouraging to have the biologist on site when something is being done expressly for wildlife management. If we expect our woodsworkers and their front-line supervisors to change their normal way of doing things, and to do the new thing well, the best way to accomplish this is by giving them firsthand information of the reasons and the expected. Don't be surprised if they come back on their own to see whether the results are there. I know that this has happened with our reforestation programs.

\section{Legislative Teeth}

At this point, I require one last thing from the profession that is now my partner in management. This is the legislative teeth to govern access, to control consumptive use and to protect where necessary. Without this, and without the political will to enforce it sensibly, management becomes little more than a futile gesture. 